\title{
Thyroidectomy in patients with a high BMI: a safe surgery?
}

\author{
J B Finel, S Mucci, F Branger, A Venara, P Lenaoures, P Rodien' ${ }^{1}$ and A Hamy \\ Département De Chirurgie Viscérale et Endocrinienne and 'Département D'Endocrinologie, \\ Centre Hospitalo-Universitaire, Angers, France
}

Correspondence should be addressed to J B Finel

Email

jbfinel@hotmail.fr

\begin{abstract}
Objective: To study and compare the specific postoperative complications of thyroidectomy in a population with a $\mathrm{BMI} \geq 25$ with a population having a BMI below 25 .

Design: A prospective study was carried out from September 2010 to January 2013.

Methods: Postoperative calcemia, laryngeal mobility, bleeding or infectious complications, postoperative hospital stay, and operation time were studied and compared statistically by a $\chi^{2}$-test or Student's $t$-test.

Results: A total of 240 patients underwent total thyroidectomy and 126 underwent a partial thyroidectomy. Of them, 168 patients had a BMI below 25 and 198 patients had a BMI $\geq 25$. There was no statistically significant difference in the occurrence of early or permanent hypoparathyroidism, recurrent laryngeal nerve palsy, bleeding complications, or postoperative duration of hospital stay. There was, however, a significant operative time in patients with a BMI $\geq 25$. Conclusion: Despite the longer operative time, thyroidectomy (total or partial) can be performed safely in patients
\end{abstract} with a $\mathrm{BMI} \geq 25$.

\section{Introduction}

Obesity and being overweight are major public health problems in France where rates of obesity have been increasing. According to the 2012 Obesity study, it is now estimated that $32 \%$ of adult population (15 million people) are overweight and 15\% (7 million people) are obese (1). This is a reflection of a trend already observed in other developed countries such as the USA, where the rate of obesity has tripled between 2007 and 2009 so that $34 \%$ of adults are obese (almost 73 million people) (2).

Therefore, more overweight and obese patients also undergo other surgical procedures apart from bariatric surgery itself. Some studies have shown a correlation between elevation of BMI and morbidity or mortality $(3,4)$.

Thyroidectomy, which was first introduced in the 12th century, is a common surgery being practiced widely; in 2010, 35367 thyroidectomies were performed in France (data obtained from health insurance and the PMSI).
This procedure has a low mortality rate but a specific morbidity (recurrent laryngeal nerve palsy, transient and permanent hypoparathyroidism, and early postoperative hematoma) $(5,6,7)$.

An American study related the outcomes of cervical endocrine surgical procedures in patients with a high BMI. They did not evaluate any endocrine-specific complications. No significant difference was found when compared with the population having a normal BMI (8).

No studies were carried out to compare the rates of specific postoperative complications of thyroidectomy between these two populations.

Therefore, the aim of this study was to compare the rates of specific postoperative complications of thyroidectomy (hypocalcemia, recurrent laryngeal nerve palsy, and early postoperative hematoma) in a population having a BMI $\geq 25$ with a population having a BMI $<25$. (c) 2014 European Society of Endocrinology Printed in Great Britain
Published by Bioscientifica Ltd. 


\section{Subjects and methods}

\section{Study design and population}

It is a prospective, observational study. It included all adults who underwent total or partial thyroidectomy between September and January 2013 in our center.

These patients were divided into two groups: one group included patients with a BMI $<25$ and the other included patients with a BMI $\geq 25$.

We excluded those patients who underwent parathyroidectomy and lymphadenectomy (recurrent laryngeal or jugular carotid).

\section{Methods}

All thyroidectomies were performed under general anesthesia by two surgeons well experienced in thyroidectomy. Operative techniques were similar for the two operators: ultraligatures vascular in contact with the glandular parenchyma or installing metal clips, capsular dissection of parathyroid glands and their vascularization, identification, if possible, of the superior laryngeal nerve in the cricothyroid space and/or the upper pole, and identification of lower laryngeal nerves (recurrent nerve) until laryngeal penetration point. Monitoring of the inferior laryngeal nerve was never used in this study because the technology was not available in the structure.

Total or partial thyroidectomies were performed as appropriate. Partial thyroidectomies are defined as lobectomy of any thyroid mass, and there was no bilateral exploration for these.

The BMI is calculated using the following formula: BMI $=$ weight $(\mathrm{kg}) /$ height $\left(\mathrm{m}^{2}\right)$. Using the World Health Organization guidelines, patients were grouped into four categories: normal (BMI, $18.5-24.9 \mathrm{~kg} / \mathrm{m}^{2}$ ), overweight $\left(25-29.9 \mathrm{~kg} / \mathrm{m}^{2}\right)$, obese $\left(30-34.9 \mathrm{~kg} / \mathrm{m}^{2}\right)$, and morbidly obese $\left(\geq 35 \mathrm{~kg} / \mathrm{m}^{2}\right)$.

In this study we divided the patients into two groups: BMI $\geq 25$ or $<25$.

We also studied demographic variables such as sex, age (18-64, 65-79, and $\geq 80$ years), and clinical characteristics of patients included in the American Society of Anesthesiologists' (ASA) classification (1-2, 3-5).

Primary clinical outcomes of interest were: rate of specific complications to thyroidectomy as postoperative hypocalcemia (transient and define), recurrent laryngeal nerve palsy (transient and define), and hematoma.

The secondary endpoints were operative time and mean duration of hospital stay.
We defined postoperative hypoparathyroidism as calcemia where serum calcium level is below $2 \mathrm{mmol} / \mathrm{l}$ $4 \mathrm{~h}$ (H4) and 2 days after surgery (D2). Corrected calcium level (CAC) is calculated as follows: $\mathrm{CAC}=$ measured Ca-0, 025 (albuminemia-40). Serum calcium is expressed in $\mathrm{mmol} / \mathrm{l}$ and serum albumin in $\mathrm{g} / \mathrm{l}$.

For light hypocalcemia (Ca, $2-2.2 \mathrm{mmol} / \mathrm{l})$ and asymptomatic hypocalcemia, no supplementation was provided. When corrected serum calcium level was $<2 \mathrm{mmol} / \mathrm{l}$ and/or the patient had symptoms such as perioral or extremities paresthesia, muscle cramps, or twitching, treatment with calcium carbonate ( $3 \mathrm{~g} /$ day) was recommended along with alfacalcidol treatment ( $3 \mu \mathrm{g} /$ day) by oral route.

The definitive hypoparathyroidism is defined as persistent hypocalcemia that requires treatment (with vitamin D and calcium) for more than 6 months.

Postoperatively, only patients with dysphonia, dyspnea, and swallowing disorders had a laryngoscopy (nasofibroscopy) to search for recurrent nerve palsy.

Any recurrent laryngeal nerve palsy that was persistent at 6 months and documented by laryngoscopy was considered as permanent palsy.

All patients were reviewed in consultation at 1 month by their endocrinologist to adapt their therapy with levothyroxine sodique and compensation of hypocalcemia if required. Patients with definitive hypoparathyroidism were reviewed by their doctor or by their endocrinologist.

\section{Statistical analysis}

Data collection was performed prospectively using a standardized report form, which included the patient's name, BMI, operative time, preoperative difficulties, and the vascular ligation technique used. Data regarding postoperative calcemia were collected at $\mathrm{H} 4$, D1, and D2 after surgery, and data regarding presence or absence of symptoms related to hypocalcemia, voice disorder, dysphagia, or dyspnea were also collected. The presence of a complication at the large thyroidlike hematoma or abscess was also reported. The form was filled by the surgical team at the discharge of each patient.

The population was divided into two groups according to the type of surgery:

Group 1: total thyroidectomy.

Group 2: partial thyroidectomy. 
These two groups were further divided into two groups depending on the BMI of the patient (greater or less than 25):

Group A: total thyroidectomy in patients with a BMI $\geq 25$.

Group B: total thyroidectomy in patients with a $\mathrm{BMI}<25$.

Group C: partial thyroidectomy in patients with a BMI $\geq 25$.

Group D: partial thyroidectomy in patients with a BMI $<25$.

Data were compared and statistically analyzed by the $\chi^{2}$-test or by Student's $t$-test using SPSS Software 16 with statistical significance set at $P \leq 0.05$.

\section{Results}

\section{Population characteristics}

A total of 366 patients were thyroidectomized (total or partial) in our unit from September 2010 to January 2013.

Based on the BMI, 21 patients (5.7\%) were morbidly obese (four had a BMI > 40), 55 (15.02\%) were obese, 122 (33.3\%) were overweight, and 168 (45.9\%) had a BMI $<25$.

Clinical and demographic characteristics of the study population were summarized in Table 1.

Most patients were women (78\%) aged 18-65 years. There was no statistically significant difference between the two populations (taking anticoagulant treatment).

Total thyroidectomy was the most performed procedure. It was performed in 240 patients, of whom

Table 1 Demographic and clinical characteristics of patients, classified into various BMI groups, undergoing thyroidectomy. $\mathrm{BMI}=$ bodyweight $(\mathrm{kg}) /$ height $\left(\mathrm{m}^{2}\right)$.

\begin{tabular}{|c|c|c|c|}
\hline & $\begin{array}{l}\text { BMI }<\mathbf{2 5} \\
n=168(\%)\end{array}$ & $\begin{array}{l}\text { BMI } \geq \mathbf{2 5} \\
n=198(\%)\end{array}$ & $P$ value \\
\hline Sex & & & $<0.05$ \\
\hline Women & $148(88.1)$ & $137(69.1)$ & \\
\hline Men & 20 (11.9) & $61(30.8)$ & \\
\hline Age group & & & $<0.05$ \\
\hline $18-65$ & $156(92.8)$ & $153(77.3)$ & \\
\hline $65-80$ & $12(7.2)$ & $45(22.6)$ & \\
\hline$>80$ & 0 & $1(0.1)$ & \\
\hline $\begin{array}{l}\text { ASA classi- } \\
\text { fication }\end{array}$ & & & $<0.05$ \\
\hline $1-2$ & $148(88.1)$ & $128(64.6)$ & \\
\hline $3-5$ & 20 (11.9) & 70 (35.4) & \\
\hline $\begin{array}{c}\text { Anticoagulant } \\
\text { treatment }\end{array}$ & $14(8.3)$ & $19(9.6)$ & 0.393 \\
\hline
\end{tabular}

145 had a BMI $\geq 25$ and 95 had a BMI $<25$. Partial thyroidectomies were performed in 126 patients, of whom 53 had a BMI $\geq 25$ and 73 had a BMI $<25$ (Table 2). Mortality was zero during this study.

\section{Complications in patients undergoing total thyroidectomy}

Postoperative hypocalcemia - As indicated in Table 3, percentages of postoperative hypocalcemia at H4 and D2 were almost similar for the two groups.

Among patients with a BMI $\geq 25$, three cases of hypocalcemia were observed at 6 months against two patients with a BMI $<25$. These diagnostics were confirmed by measuring corrected calcemia, and these five patients required a substitutive therapy.

There was no statistically significant difference between the two groups $(P=0.79)$.

Recurrent laryngeal nerve palsy $\bullet$ Eight patients in group A (including one patient who presented with a bilateral paralysis) and three patients in group B had early recurrent laryngeal nerve palsy. There was no statistically significant difference between the two groups $(P=0.14)$.

Three patients $(1.45 \%)$ had final recurrent laryngeal nerve palsy confirmed by fibroscopy (two patients in group A and one in group B). Thanks to speech therapy, the voice was almost normal.

Bleeding complications $>$ Two patients in group A and one in group $\mathrm{B}$ presented with a hematoma requiring a return to the operating room. There was no statistically significant difference between the two groups $(P=0.82)$.

Operative time $>$ Compared with normal BMI patients, patients with a BMI $\geq 25$ had a higher operative time. There was a statistically significant difference between the two groups $(P=0.007)$.

Postoperative duration of hospital stay $>$ The mean duration of hospital stay was 2.49 days for all patients.

It was 2.52 days for patients in group A and 2.44 days for those in group B. There was no statistically significant difference between the two groups $(P=0.57)$.

Weight of thyroid gland $\downarrow$ The mean weight of thyroid gland was $51.78 \mathrm{~g}$ for patients in group A and $42.38 \mathrm{~g}$ for those in group B. There was no statistically significant difference between the two groups $(P=0.096)$. 
Table 2 Population distribution.

\begin{tabular}{|c|c|c|c|}
\hline & $\begin{array}{l}\text { Total thyroid- } \\
\text { ectomy, } n=240\end{array}$ & $\begin{array}{l}\text { Partial thyroid- } \\
\text { ectomy, } n=126\end{array}$ & $\begin{array}{c}\text { Total, } \\
n=366\end{array}$ \\
\hline BMI $\geq 25$ & 145 & 53 & 198 \\
\hline BMI $<25$ & 95 & 73 & 168 \\
\hline
\end{tabular}

\section{Complications in patients undergoing partial thyroidectomy}

Postoperative hypocalcemia $>$ None of the patients $(0 \%)$ in subgroup C but one patient (1.37\%) in subgroup D had an early postoperative hypocalcemia $(P=0.242)$. This was normalized after 1 month.

No hypocalcemia was finally detected in patients undergoing partial thyroidectomy (Table 4).

Recurrent laryngeal nerve palsy - Three patients had transient recurrent laryngeal nerve palsy; two in subgroup $C$ and one in subgroup D. There was no statistically significant difference $(P=076)$. None of the patients had final recurrent laryngeal nerve palsy.

Bleeding complications $\downarrow$ Four patients (two from each group) required reoperation for hematoma. There was no statistically significant difference between the two groups $(P=0.74)$.

Operative time $>$ The mean operative time was $72.6 \mathrm{~min}$ in subgroup $C$ and 70.3 min in subgroup D. There was no statistically significant difference $(P=0.67)$.

Postoperative duration of hospital stay - The mean postoperative duration of hospital stay was 2.07 days for patients in subgroup D against 2.08 days for those in subgroup C. There was no statistically significant difference between the two groups $(P=0.95)$.

Weight of thyroid gland - The mean weight of thyroid gland was $27.51 \mathrm{~g}$ for patients in subgroup $\mathrm{C}$ and $22.48 \mathrm{~g}$ for those in subgroup $D$. There was no statistically significant difference between the two groups $(P=0.34)$.

\section{Pathological results}

As indicated in Table 5, patients with a BMI > 25 tend to present with more papillary, follicular, and medullary cancers than patients with a BMI below 25. The same trend is also observed in cases of Graves' disease or the presence of multinodular goiter. There was no statistically significant difference between the two groups.

There were more pT1 in patients with a BMI $>25$ than in patients with a BMI $<25(P=0.045)$. There was no statistically significant difference between the two groups for $\mathrm{T}_{2}$ and $\mathrm{T}_{3}$ papillary or follicular cancer.

\section{Discussion}

For many surgeons, it is often regarded as established that patients with a high BMI would present more often with postoperative complications when compared with patients having a normal BMI $(8,9)$.

But this perception is not supported by the existing literature and controversy remains about the relationship between obesity and outcomes after any type of surgery.

Studies comparing endocrine-specific complications of endocrine surgery between overweight or obese patients and others are rare and, to our knowledge, there are no studies comparing endocrine-specific complications of thyroidectomy.

This study is the first to compare the endocrinespecific early complications of thyroidectomy between overweight or obese patients and patients with a BMI $<25$. We studied specific complications that occurred after thyroidectomy, such as hypoparathyroidism, recurrent laryngeal nerve palsy, and hematoma.

Some authors have demonstrated that a high BMI is an independent predictor of mortality. The largest study included over 80000 patients who underwent coronary

Table 3 Follow-up of patients undergoing total thyroidectomy.

\begin{tabular}{|c|c|c|c|}
\hline & Subgroup A & Subgroup B & \\
\hline & $\begin{array}{c}\text { BMI } \geq 25 \\
n=145(\%)\end{array}$ & $\begin{array}{l}\mathrm{BMI}<25 \\
n=95(\%)\end{array}$ & $P$ value \\
\hline \multicolumn{4}{|l|}{$\begin{array}{l}\text { Early postoperative } \\
\text { hypocalcemia }\end{array}$} \\
\hline $\mathrm{H} 4$ & $6(4.14)$ & $4(4.21)$ & 0.96 \\
\hline D2 & $16(11.1)$ & $10(10.75)$ & 0.89 \\
\hline $\begin{array}{l}\text { Definitive hypocalcemia } \\
\text { (6 months) }\end{array}$ & $3(2.06)$ & $2(2.1)$ & 0.79 \\
\hline $\begin{array}{l}\text { Transient recurrent lar- } \\
\text { yngeal nerve palsy }\end{array}$ & $8(5.5)$ & $3(3.15)$ & 0.14 \\
\hline $\begin{array}{l}\text { Final recurrent laryngeal } \\
\text { nerve palsy }\end{array}$ & $2(1.38)$ & $1(1.05)$ & 0.82 \\
\hline Hematoma & $2(1.38)$ & $1(1.05)$ & 0.82 \\
\hline Operative time (min) & 103.7 & 91.55 & 0.007 \\
\hline $\begin{array}{l}\text { Postoperative duration } \\
\text { of hospital stay (days) }\end{array}$ & 2.52 & 2.44 & 0.057 \\
\hline $\begin{array}{l}\text { Weight of thyroid gland } \\
\text { (g) }\end{array}$ & 51.78 & 42.38 & 0.096 \\
\hline
\end{tabular}


Table 4 Follow-up of patients undergoing partial thyroidectomy.

\begin{tabular}{|c|c|c|c|}
\hline & Subgroup C & Subgroup D & \\
\hline & $\begin{array}{l}\text { BMI } \geq 25 \\
n=53(\%)\end{array}$ & $\begin{array}{l}\text { BMI <25, } \\
n=73(\%)\end{array}$ & $P$ value \\
\hline \multicolumn{4}{|l|}{$\begin{array}{l}\text { Early postoperative } \\
\text { hypocalcemia }\end{array}$} \\
\hline $\mathrm{H} 4$ & $1(1.88)$ & 0 & 0.242 \\
\hline $\mathrm{D} 2$ & 1 & 0 & \\
\hline $\begin{array}{l}\text { Definitive hypocalcemia } \\
\text { (6 months) }\end{array}$ & 0 & 0 & \\
\hline $\begin{array}{l}\text { Transient recurrent } \\
\text { laryngeal nerve palsy }\end{array}$ & $2(3.77)$ & $1(1.37)$ & 0.76 \\
\hline $\begin{array}{l}\text { Final recurrent laryn- } \\
\text { geal nerve palsy }\end{array}$ & 0 & 0 & \\
\hline Hematoma & $2(3.77)$ & $2(1.58)$ & 0.74 \\
\hline Operative time (min) & 72.6 & 70.3 & 0.67 \\
\hline $\begin{array}{l}\text { Postoperative duration } \\
\text { of hospital stay (days) }\end{array}$ & 2.08 & 2.07 & 0.95 \\
\hline $\begin{array}{l}\text { Weight of thyroid } \\
\text { gland (g) }\end{array}$ & 27.51 & 22.48 & 0.34 \\
\hline
\end{tabular}

bypass and demonstrated that an elevated BMI was an independent predictor of morbidity and mortality (10).

Two other important studies demonstrated contradictory results. In a large, prospective monocentric study, Dindo et al. reported about 6336 patients undergoing various elective general surgical procedures. Despite higher rates of diabetes, hypertension, and coronary disease in obese patients, the morbidity rates among patients with a BMI $\geq 30$ and those with a BMI $<30$ were very similar (15.1 vs $16.3 \%, P=0.26$ ). Duration of hospital stay after surgery did not differ between the two groups. Only the incidence of surgical site infection was higher in obese patients when laparotomy was performed (4 vs $3 \%, P=0.03$ ) (9).

Another recent study in this field was carried out in 2013 by Melis et al. It included 540 patients with adenocarcinoma who underwent esophagectomy (11). Of them, 155 patients were normal weight, 198 were overweight, and 197 were obese. There was no significant difference in operative time (288 vs $272 \mathrm{~min}, P=0.2$ ) and mortality between obese patients and others. This study concluded that obesity did not impact the morbidity and mortality after esophagectomy. R0 resection and quality of lymphadenectomy were the same in both groups. Esophagectomies could be performed safely and efficiently in overweight and obese patients.

Although its consequences are often more serious than recurrent laryngeal nerve palsy, hypocalcemia is the most worrisome complication of total thyroidectomy. It often increases the duration of hospitalization to detect and treat tetany (12). The majority of hypocalcemia cases are transient and resolve spontaneously. In the literature, transient hypoparathyroidism after thyroidectomy seems to be common (1.6-50\% of interventions) (13). In this study, we had $4.16 \%$ of hypocalcemia at $\mathrm{H} 4$ and $10.8 \%$ at D2 with a greater tendency to D2 hypoparathyroidism in patients with a BMI > 25 (11.1 vs $10.75 \%)$ but which is not statistically significant. Thyroidectomy in patients with a BMI $>25$ does not seem to increase the rate of transient hypoparathyroidism when compared with surgery in patients with a normal BMI.

Calcemia was measured at $\mathrm{H} 4$ and D2 because the nadir of postoperative calcemia is obtained between 24 and $48 \mathrm{~h}$ after thyroidectomy (14).

There is a net increase in hypocalcemia between H4 and D2 postoperatively. There are early predictive markers of hypoparathyroidism that would allow early initiation of replacement therapy.

Lecerf et al. (13) studied a series of 137 patients who underwent total thyroidectomy. The level of serum parathyroid hormone (PTH) was measured preoperatively and $4 \mathrm{~h}$ postoperatively. Sensitivity and specificity of the PTH levels with a threshold of $19.4 \mathrm{ng} / \mathrm{ml}$ to detect hypocalcemia in $\mathrm{H} 4$ postoperatively were 84.6 and $92.9 \%$ respectively with an overall accuracy of $90.5 \%$. The relative decreases between preoperative and postoperative PTH levels have been analyzed. The threshold of PTH decline of $68.5 \%$ has sensitivity, specificity, and positive and negative predictive values of $97.4,95.9$, and 98.9 and $90.5 \%$ respectively. The overall accuracy was $96.4 \%$. This method, which is fast and reliable, could help with thyroid outcome surgery, because the surgeon gets the results within $5 \mathrm{~h}$ postoperatively. Furthermore, patients with a

Table 5 Pathological results of patients undergoing thyroidectomy.

\begin{tabular}{|c|c|c|c|}
\hline & $\begin{array}{l}\text { BMI }<\mathbf{2 5}, \\
n=168(\%)\end{array}$ & $\begin{array}{l}\text { BMI } \geq \mathbf{2 5} \\
n=198(\%)\end{array}$ & $P$ value \\
\hline $\begin{array}{l}\text { Papillary } \\
\text { cancer }\end{array}$ & $25(14.8)$ & $32(16.16)$ & 0.68 \\
\hline $\begin{array}{l}\text { Medullary } \\
\text { cancer }\end{array}$ & 0 & $2(1.01)$ & 0.191 \\
\hline $\begin{array}{l}\text { Follicular } \\
\text { cancer }\end{array}$ & $3(1.79)$ & 8 & 0.44 \\
\hline $\begin{array}{l}\text { Multinodular } \\
\text { goiter }\end{array}$ & 91 & 121 & 0.066 \\
\hline $\begin{array}{l}\text { Graves' } \\
\text { disease }\end{array}$ & $10(5.9)$ & $12(6.06)$ & 0.965 \\
\hline \multicolumn{4}{|l|}{ TNM } \\
\hline T1 & 15 & 41 & 0.045 \\
\hline $\mathrm{T} 2$ & 3 & 6 & 0.18 \\
\hline T3 & 1 & 6 & 0.12 \\
\hline $\mathrm{N}+$ & 0 & 3 & 0.09 \\
\hline
\end{tabular}


higher risk of hypocalcemia can receive calcium and vitamin D supplementation before symptoms appear.

In obese patients, the basic rate of PTH is higher when compared with the general population probably due to vitamin D deficiency (15). There are no current studies comparing the PTH rate and PTH decline after thyroidectomy in overweight or obese patients.

Therefore, this method cannot be performed at this time in patients with a BMI $>25$.

Some patients suffering from resection or irreversible injury of the parathyroid glands have a definitive hypoparathyroidism. This complication requires replacement therapy and monitoring forever to avoid the sometimes dramatic complications of chronic hypocalcemia (16).

Many studies on the final hypoparathyroidism after thyroidectomy were published with results ranging from 0 to $13 \%$ (17). In the study 'CATHY', the rate of postoperative hypoparathyroidism was $2.7 \%$ (18). Unfortunately, they do not all agree on the exact definition of definitive hypoparathyroidism and postoperative period to affirm it.

We defined definitive hypoparathyroidism as the requirement for treatment with vitamin $\mathrm{D}$ and calcium for more than 6 months. PTH levels at 6 months were not taken into account to define the permanent hypocalcemia.

The incidence of this complication in our study was slightly lower in patients with a BMI below 25, but there was no statistically significant difference (1.05 vs $1.38 \%$ ). These rates are lower than those in the literature, but excluded all patients in whom lymphadenectomy was performed. It is established that cervical lymphadenectomy increases the risk of hypoparathyroidism.

In lymphadenectomy, there was no association between the BMI $(>25)$ and definitive postsurgical hypoparathyroidism.

Transient recurrent laryngeal nerve palsy after total thyroidectomy is reported in $0-7 \%$ of cases. It is definitive in $1 \%(19,20)$.

In this study, we found that $1.45 \%$ of patients had final recurrent laryngeal nerve palsy. We have not highlighted any statistically significant difference between patients with a BMI $>25$ and those with a BMI $<25$.

In a large USA study (8), Buerba et al. studied 26864 patients who underwent thyroidectomy or parathyroidectomy. The rate of postoperative complications in patients with a high BMI was compared with those having a normal BMI. They did not evaluate such endocrinespecific complications as recurrent laryngeal nerve palsy or hypocalcemia. They found the duration of operation to be longer in patients with a high BMI, which was explained by a higher proportion of general anesthesia in patients with a high BMI, a longer duration of operation, and increased difficulty in positioning. In addition, patients with a greater BMI have greater complication rates (urinary and wound occurrence).

In this study, we did not find any difference in the occurrence of hematoma between the two groups.

These patients tend to have a longer duration of hospital stay than patients with a BMI $<25$. This difference is not statistically significant but the $P$ value is $\sim 0.05$.

However, there is a statistically significant increase in operative time of total thyroidectomy between the two groups. This increase in operative time is neither due to the type of anesthesia, because all thyroidectomies were performed under general anesthesia, nor due to the surgeon's experience, as the same two operators performed all the thyroidectomies included in this study. However, it is more difficult to have a good surgical exposure. Owing to their overweight, patients with a high BMI often have a morphology resulting in a wider and shorter neck than patients with a BMI $<25$. In addition, parathyroid may get confused (because of their color) with adipose tissue, which makes it more difficult to locate and dissect. This leads to an increased operative time.

It is recognized that a surgeon's experience may affect the operative time. Indeed, in CATHY (18), it is shown that surgeons with extensive experience and aged between 35 and 50 years are those with the least rate of postoperative complications. In multivariate analysis, it is recognized that an experience of 20 years and above in surgical practice was correlated with an increased rate of recurrent laryngeal nerve palsy and hypoparathyroidism.

\section{Conclusion}

Many surgeons think that operating on patients with a high BMI is technically challenging and leads to worse outcomes. This study is in contradiction with this thought. We do not show any significant difference in the specific rate of postoperative complications in thyroidectomy. However, we highlight a longer operative time probably due to intraoperative difficulties. But this increase in operative time does not seem to have any impact on the duration of hospital stay. Therefore, thyroidectomy can be performed safely in overweight and obese patients.

For a study involving a larger number of patients even from multicenters, it seems to be necessary that the study 
has to be carried out extensively and statistically significant results have to be obtained.

\section{Declaration of interest}

The authors declare that there is no conflict of interest that could be perceived as prejudicing the impartiality of the research reported.

\section{Funding}

This research did not receive any specific grant from any funding agency in the public, commercial or not-for-profit sector.

\section{References}

1 OBEPI. ObEpi-Roche2012. Enquête épidémiologique nationale sur le surpoids et l'obésité; available from http//www.roche.fr/portal/ roche-fr/obepi_2012, 2012.

2 Charles MA. Obesity: what epidemiology tells us? Cahiers de Nutrition et de Diététique 201146 167-172. (doi:10.1016/j.cnd.2011.04.001)

3 Fleming JB, Gonzalez RJ, Petzel MQ, Lin E, Morris JS, Gomez H, Lee JE, Crane CH, Pisters PW \& Evans DB. Influence of obesity on cancerrelated outcomes after pancreatectomy to treat pancreatic adenocarcinoma. Archives of Surgery 2009144 216-221. (doi:10.1001/archsurg. 2008.580)

4 Van Straten AH, Bramer S, Soliman Hamad MA, van Zundert AA, Martens EJ, Schonberger JP \& de Wolf AM. Effect of body mass index on early and late mortality after coronary artery bypass grafting. Annals of Thoracic Surgery 201089 30-37. (doi:10.1016/j.athoracsur.2009.09.050)

5 Randolph GW, Kobler JB \& Wilkins J. Reccurent laryngeal nerve identification and assessment during thyroid surgery: laryngeal palpation. World Journal of Surgery 200428 755-760. (doi:10.1007/ s00268-004-7348-x)

6 Harnes JK, Fung L, Thompson NW, Burney RE \& McLeod MK. Total thyroidectomy: complications and technique. World Journal of Surgery 198610 781-786. (doi:10.1007/BF01655238)

7 Lo CY, Kwok KF \& Yuen PW. A prospective evaluation of recurrent laryngeal nerve paralysis during thyroidectomy. Archives of Surgery 2000 135 204-207. (doi:10.1001/archsurg.135.2.204)

8 Buerba R, Roman SA \& Sosa JA. Thyroidectomy and parathyroidectomy in patients with high body mass index are safe overall: analysis of
26,864 patients. Surgery 2011150 950-958. (doi:10.1016/j.surg. 2011.02.017)

9 Dindo D, Muller MK, Weber M \& Clavien PA. Obesity in general elective surgery. Lancet 2003361 2032-2035. (doi:10.1016/S01406736(03)13640-9)

10 Wagner BD, Grunwald GK, Rumsfeld JS, Hill JO, Ho PM, Wyatt HR \& Shroyer AL. Relationship of body mass index with outcomes after coronary artery bypass graft. Annals of Thoracic Surgery 200784 10-16. (doi:10.1016/j.athoracsur.2007.03.017)

11 Melis M, Weber J, Shridhar R, Hoffe S, Almhanna K, Karl R \& Meredith K. Body mass index and perioperative complications after oesophagectomy for adenocarcinoma: a systematic database review. BMJ Open 20133 e001336. (doi:10.1136/bmjopen-2012-001336)

12 Reber PM \& Heath H. Hypocalcemic emergencies. Medical Clinics of North America 199579 93-106.

13 Lecerf P, Orry D, Perrodeau E, Lhommet C, Charretier C, Mor C, Valat C, Bourlier P \& de Calan L. Parathyroid hormone decline 4 hours after total thyroidectomy accurately predicts hypocalcemia. Surgery 201230 863-868. (doi:10.1016/j.surg.2012.03.011)

14 Grodski S \& Serpell J. Evidence for the role of perioperative PTH measurement after total thyroidectomy as a predictor of hypocalcemia. World Journal of Surgery 200832 1367-1373. (doi:10.1007/s00268008-9545-5)

15 Bell NH, Epstein S, Greene A, Shary J, Oexmann MJ \& Shaw S. Evidence for alteration of the vitamin D-endocrine system in obese subjects. Journal of Clinical Investigation 198576 370-373. (doi:10.1172/ JCI111971)

16 Bellamy RJ \& Kendall-Taylor P. Unrecognized hypocalcaemia diagnosed 36 years after thyroidectomy. Journal of the Royal Society of Medicine $1995 \mathbf{8 8}$ 690-691.

17 Gourin CG \& Johnson JT. Postoperative complications. In Surgery of the Thyroid and Parathyroid Glands, 1st edn, pp 433-443. Ed GW Randolph. Philadelphia: W.B. Saunders, 2003.

18 Duclos A, Peix JL, Colin C, Kraimps JL, Menegaux F, Pattou F, Sebag F, Touzet S, Bourdy S, Voirin N et al. Influence on performance on individual surgeons in thyroid surgery: prospective cross sectional multicentre study. BMJ 2012344 d8041. (doi:10.1136/bmj.d8041)

19 Rosato L, Mondini G, Ginardi A, Clerico G, Pozzo M \& Raviola P. Incidence of complications of thyroid surgery. Minerva Chirurgica 2000 55 693-702.

20 Hermann M, Alk G, Roka R, Glaser K \& Freissmuth M. Laryngeal recurrent nerve injury in surgery for benign thyroid diseases: effect of nerve dissection and impact of individual surgeon in more than 27,000 nerves at risk. Annals of Surgery 2002235 261-268. (doi:10.1097/ 00000658-200202000-00015)

Received 22 January 2014

Revised version received 4 April 2014

Accepted 22 April 2014 